\title{
English Animal Idioms under Event-domain Cognitive Model and Salience View
}

\author{
Zhimin Xiang \\ Sichuan Preschool Educators College \\ Mianyang, Sichuan, China 621709
}

\begin{abstract}
Event-domain cognitive model is a significant theoretical model in cognitive linguistics. Salience view is another important principle to account for various linguistic structures in cognitive linguistics. The present paper is aimed at the interpretation of cognitive mechanism and linguistic functions of English animal idioms from the perspectives of ECM and salience view.
\end{abstract}

Keywords-event-domain cognitive model; ECM; salience view; English animal idioms

\section{INTRODUCTION}

It is well known that the ability to use language is the most distinguished property that sets us human beings from the rest of other species. A most widely accepted definition of language is "a system of sounds and symbols used for human communication." Language is unique to human beings and language is an indispensible part and parcel of our life. Language is the single best evolution in human history. Without language the arts, sciences and other human constructs could not come into being in the first place. Many linguists are in consensus about the view that language is a prerequisite for the development of human civilization. Essentially, language serves as a medium for human communication. Language is a meaningful hierarchy of sounds and symbols especially designed for human interaction.

However significant language as a whole system is, it won't be an integral and organic whole without some of its most important components, for example idioms. Idioms are relatively set meaningful chunks of a language and its corresponding culture. However, idioms are often easy to come by while hard to understand and still harder to use appropriately. The adroit and felicitous use of idioms in a language is often a testament to a person's command of the language. English animal idioms rich in cultural implications account for a great part in English idioms. Take the most well-known animal idiom "love me, love my dog" for example. It is so vivid that it is ever ready to be employed to denote the meaning "If you love me, love me as a whole person and accept everything about me". It is to our satisfaction that idioms as a whole has been under heavy discussion of various schools of linguistics and attracted a lot of attention of many academics. Yet with the literature at hand we have to say that animal idioms as a subspecies of English idioms haven't got the research limelight it deserves.
While we do have observed some remarkable attempts in this regard, we are not quite satisfied with the research status-quo in this niche field. The main purpose of the thesis is to interpret the cognitive mechanism and linguistic functions of English animal idioms from the perspectives of ECM (eventdomain cognitive model) and salience view. The first section examines the close relationship between idioms and culture. It sheds light on the significance of the present study and offers a glimpse into the inevitable difficulties English idioms as a whole has afforded English language learners. The most challenging part in learning English idioms is cultural context and its implications. Something that seems common sense in one culture has to be spelled out in great details in another culture. The second section lays out the framework of the present study: event-domain cognitive model and salience view. Then on the basis of this new theoretical framework, we set out to a new reclassification of English animal idioms: event-type animal idioms and actiontype idioms. In the third section, we point out the three aspects of culture differences affecting animal idiom study: regional cultural differences, historical cultural differences and conventional cultural differences. Some examples are provided for the interpretation of animal idioms under the new theoretical framework and the illustration of the cultural differences. Section three is the main body of the thesis. Finally, we come to the conclusion part of the thesis. In the conclusion part, we tend to underscore the significance of the present study. In a nutshell, this paper contributes to a specific inquiry into the niche subgroup of English idioms rather than a general study of English idioms. We hope that this study can serve as a meaningful attempt in the field of English idiom study.

\section{THE CLOSE RELATIONSHIP BETWEEN IDIOMS AND Culture}

\section{A. Basic Concepts of Culture}

To have a simple definition of culture, culture refers to the total way of life of people in a specific linguistic community. This kind of definition indicates that culture means the total of customs, traditions, values, beliefs held collectively by a society. In a nutshell culture can be classified into two types; one is material objects, including all visible items such as food, clothes, building, and other physical identities, etc. Besides material items, there is another kind of culture which is not so visible or substantial. 
It is mainly represented by the convention, beliefs, values, mode of thinking, etc. Although this kind of culture accounts for a relatively smaller percentage of culture compared with material objects, it is more fundamental. In other words, it is the crystallization of all the past productive and living patterns of a speech community and it underpins the material substantiation of the first type of culture. Without this layer of culture the various physical manifestations of culture can simply never come into being in the first place. While we admit that the tangible products of the mind is more eyecatching, we do observe that abstract and hidden aspects of culture are indeed very elusive and therefore pose a myriad of problems to foreign language learners. And the plot thickens when the two languages in question belong to different culture spheres.

\section{B. Interaction between Idioms and Culture}

Idioms are one of the finest crystallizations of the collective linguistic wisdom of a speech community. Language users who belong to the same linguistic community have their own distinctive ways in denoting concepts and express their value systems. A case in point would be the mental association of the imaginary creature "dragon" in Chinese and English culture. While in Chinese the word "dragon" usually designates something majestic and felicitous, in English this word inevitably stands for a monster which spits fire and wreaks great havoc on people's life. And people with a smattering knowledge of Chinese culture couldn't fail to notice that in the ancient, feudalistic dynasties in Chinese history, the word dragon itself and its image actually stood for the king or emperor. It is even said that the Chinese are descendents of the dragon. The worship of dragon in China may be related to the legend that the dragon is a combination of nine majestic animals like snake, deer, tiger, etc and marvelously adaptive to different environments. It can fly in the sky, crawl on the land and dive into deep water. It can hide or manifest itself to rise to different occasions. Therefore this ubiquitous presence and impressive versatility partly accounts for its popularity in Chinese culture. In a word, the word "dragon" is deemed as an auspicious symbol and supposedly brings good luck, for it has magic power. So the word has given rise to a legion of idioms in Chinese such as "wang zi cheng long"-longing to see one's offspring become dragons, that is to say, become successful and have promising futures, and "long teng hu yue"-literally means "dragons rising and tigers leaping" and actually describes a hive of bustling activity. However, in the English culture, the dragon is more often than not a symbol of evil. For example in English the idiom "the old dragon" means "devil" and even the word "dragon" itself is often used to mean a tough person especially an old woman who never goes easy on her custodian. From the above contrastive discussion, it is clear that the associative and affective meanings of the word "dragon" in the Chinese and English-speaking linguistic communities are a world of difference. This example bears out that culture has shaped language in a big measure and language in the other way around is a mirror of culture. With the close interaction between language and culture in mind, next we tend to offer a new framework for the interpretation of animal idioms in English.

\section{THE FRAMEWORK OF THE PRESENT STUDY AND RECLASSIFICATION OF ENGLISH ANIMAL IDIOMS}

Cognitive linguistics is an increasingly prominent branch of linguistic study in recent years. It refers to the school of thought within linguistics that holds the claim that between language and the world there is another intermediary processing layer namely human's cognition. And human's cognition often takes the form of concepts which are specific to contexts. Cognitive linguistics forms a sharp contrast to the historically dominant position of Noam Chomsky and his generative grammar. Instead it aims to explain the various cognitive mechanisms behind the acquisition, production and understanding of language. By adhering to the central theoretical claim that there is not an autonomous linguistic faculty in the mind of language user and knowledge of language comes from language use, cognitive linguistics purports to claim that meaning is conceptualization and language is both embodied and situated in a specific environment.

Another key topic in cognitive linguistics is the generating motives behind various linguistic constructions. So far a number of cognitive linguists have proposed different theoretical models concerning the topic in question. For example Talmy $(1985,1988)$ has put forward a forcedynamic model to explain some conceptual structures and corresponding linguistic constructions, Lakoff (1987) have come up with a bold theoretical hypothesis namely spatialization of form hypothesis to account for six kinds of conceptual structures and their respective syntactic constructions; and Langacker $(1991,2002)$ formulated two theoretical models namely billiard-ball model and stage model to shed light on all the basic syntactic structures in English, for example the "S+V", "S+V+O", " $\mathrm{S}+\mathrm{V}+\mathrm{C}$ ", etc and their variations. All these attempts are both daring and inspiring. Yet Wang Yin (2005) claims that there are, to some degree, certain deficiencies in these aforementioned theoretical models: first, all these models are processing along a linear sequence to the neglect of the hierarchy of different components in an event, second, their analysis is mainly aimed at dynamic events or scenarios without due consideration of other equally important static properties of an event; third, all these hypotheses is so set on the motives behind syntactic constructions that other layers of language, for instance semantics, the text as a whole rarely got enough research limelight which they equally deserves.

In light of all these deficiencies in the previous theoretical models, Wang (2005) has come up with a new theoretical model called event-domain cognitive model (ECM). Under this theoretical model, the basic unit for conceptualization in language is called an "event", it is a way for us to experience the world and a measuring unit to the derived knowledge chunks from our interaction with the world. And an event is made up of two components, namely "action" and "being". Furthermore an action constitutes both dynamic behaviors and static behaviors and comprises many typical defining properties which he designates with D1...Dn. 
In addition, a being again comprises many individual entities B1...Bn. And all these individual entities have their confining properties which Wang conveys with $\mathrm{C} 1 \ldots \mathrm{Cn}$. The whole model looks like the following diagram "Fig. 1":

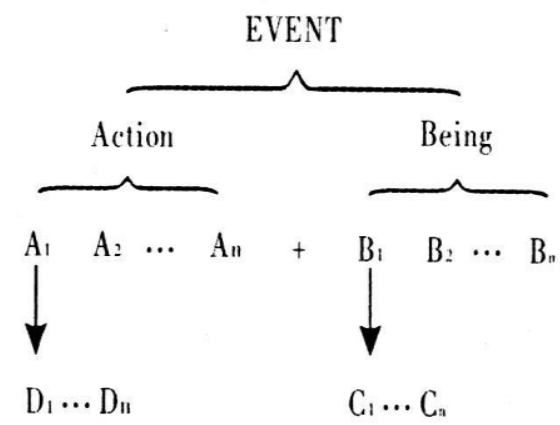

Fig. 1. Event-domain cognitive model, Wang Yin, 2005, p.240

Now equipped with this theoretical model, we can reclassify English animal idioms into two subcategories, namely action-based animal idioms and being-based animal idioms. For the former, we have animal idioms like "go ape over something (go crazy about something)", "strut like a peacock (swagger)" or "have other fish to fry (have other things to do)", etc. And for the latter we have "as blind as a bat", "as happy as a clam", and "cat among the pigeons", etc. All these animal idioms are so vivid that they always stick in our memory once we get to see them. And we do observe that the defining or confining properties in either actionbased animal idioms or being-based animal idioms bring out the most salient aspect of these animal idioms.

Speaking of cognitive mechanisms, we have another important cognitive principle in cognitive linguistics. It is called "salience view". According to this view, all of our cognitive activities are guided by salience, which is to say, of all the aspects in an activity or entity, we can't process every aspect with equal attention and due to this partiality of attention allocation different aspects of an activity or entity come into our focus. And this view, first put forward by Danish psychologist Rubin, is best illustrated by the facevase illusion devised by him "Fig. 2":

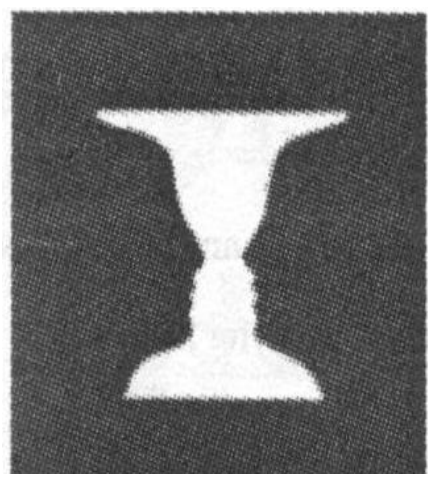

Fig. 2. Face-vase illusion, Rubin

In the above face-vase illusion, we can see two opposing black human faces or one white vase at a time. Both interpretations are reasonable from different focal points, but one can't see both human faces and the vase at the same time. Both the human face and vase can become the more salient figure, but when the human face or vase becomes the figure, the other part has to become the corresponding background. Applying this theoretical perspective to our present study, we often find that in either generating or interpreting one single idiom, we have to, willing or not, make a choice in different aspects of one single action or being, and due to the different focal points we choose, we derive different idioms from the same animal. In the next section, we are going to make a more detailed study of English animal idioms under the new classification: action-based animal idioms and being-based animal idioms.

\section{INTERPRETATION OF ENGLISH ANIMAL IDIOMS UNDER ECM}

In order to make our discussion more specified, we tend to divide the English animal idioms again into three large categories: domesticated animal idioms, wild animal idioms, mythical animal idioms. And under every large category, we will further elaborate our discussion along the line of two sub-categories: action-based animal idioms and being-based animal idioms.

\section{A. Domesticated Animal Idioms}

1) Action-based domesticated animal idioms: Throughout human history, especially when we have entered the agricultural phase of human civilization, domesticated animals have been all too familiar a presence in our daily lives. East or west, we have dogs for guarding our home and keeping us company, cattle for grazing, and horses or donkeys for burden-bearing. Due to some regional cultural differences we may have more cattle for ploughing in China while in England farmers tend to use horses. While differences do exist, we find similarities are also too many to ignore.

Talking about domesticated animal, a familiar word "dog" will come into the minds of both westerners and easterners. Take "fell two dogs with one stone" for example. This is a typical action-based domesticated animal idiom. Actually in English we have another idiom with the same meaning namely "kill two birds with one stone". And also in Chinese we have "yi jian shuang diao" to mean achieve two aims with one single action.

Another dog idiom is "fight like cats and dogs", which means a fierce fight between two opponents. It is common sense that under the same roof, it is nine out of ten that cats and dogs don't get along with each other, so this dog idiom presents no difficulties for English learners.

One aspect concerning dog idioms that calls for our attention is that while Chinese think lowly of dogs and have idioms like "zhu gou bu ru( even lower than pigs or dogs)", English communities usually equal dogs with persons. In English culture, dogs are family members who keep company of their human friends. Hence we have "a lucky dog" to mean a lucky person and "give a dog a bad name and hang him" to mean a person is sometimes his reputation. 
Besides the dog idiom "every dog has its day" is the best illustration which bears the fact that in English culture a dog and a person are on equal terms.

These action-based dog idioms are abundant in English culture. For example, we have "go to the dogs" to mean one's condition has worsened. And if we "help a lame dog over a stile", we give a helping hand to those desperately in need of help. Furthermore, the ideal picture in our mind for our Mr. or Mrs. Right is someone who can "love me, love my dog".

2) Being-based domesticated animal idioms: Again we will have dog idioms for exemplification since dog is the most typical domesticated animal. First we have "like a dog with two tails" to describe someone who is very happy. In the being "dog" there are so many properties that have the potential to be singled out to form idioms. In this idiom it is the "tail" that comes into our focus. We know that a dog usually displays his emotion through his tail, and a dog typically wags his tail if he sees his master. The faster he wags his tail, the more delighted he is. In this scenario, if a dog has two tails, then he has more resources to display his emotion. Hence the idioms "like a dog with two tails" come into being.

In this idiom, once the "tail" aspect gets singled out and becomes the figure, other features of dog as a being become its background. And another point we want to stress is that we do observe that being-based animal idioms and actionbased animal idioms sometimes overlap. Take "dressed/done up like a dog's dinner" for example. This dog idiom contains a typical verb past-tense form dressed/done, yet it also includes "a dog's dinner" as a part of the "dog" being. So sometimes the classification based on action or being is only for the convenience of our discussion while in real English animal idiom world, the picture is much more complicated and some overlapping cases do exist under our reclassification criterion.

Furthermore, the reason why we employ the dog metaphor for analysis is that dogs are the most familiar domesticated animal in the eastern and western world. For domesticated animal idioms, we have quite a lot besides dog idioms. For instance we have "sheep among wolves", "lost/wandering sheep", "sort out the sheep from the goats", "as drunk as Davy's sow", "grease a fat sow", "like a sow playing a trumpet", "make a silk purse out of a sow's ear", "send a sow to Minerva", etc. Examples abound while we do have limited space to give them a thorough discussion.

\section{B. Wild Animal Idioms}

1) Action-based wild animal idioms: Birds serve as a typical example of wild animals. For action-based bird idioms, we have "A little bird told/whispered to me" to signify an information source which we would rather not to clarify. And we use "birds of a feather flock together" to mean kindred souls always come together; still if a person eats very little, we can describe him/her as "eat like a bird".
2) Being-based wild animal idioms: For birds, they not only can have many actions like "to tell/whisper", "to flock"; "to eat", they can also have many features that can be selected to form idioms. In this selection process, we are actually guided by the salience view. In other words, we can't simply wrap all the features of the being "bird" into one single bird idiom. Therefore we have the following being-based yet feature-specific bird idioms:

A bird in the hand (a mission accomplished)

A bird in the bush (an aim still not accomplished)

As free as a bird (a person who is without any constraints)

Bird of ill omen (a person who brings bad message)

Bird of passage (a person with no set itinerary)

Early bird (a person who gets up or acts early)

Top bird of the nest (the high-flier in a family)

Tough old bird (someone old yet unyielding)

In the above being-based bird idioms, different features of birds are shed light on in the same event-based cognitive domain: bird. And due to the effect of the salience view, different features of bird get our attention and finally give rise to different bird idioms.

Apart from birds, we have a myriad of wild animal idioms in English culture. For action-based wild animal idiom we have "rise/be up/get up with the lark", "go ape over/for something", "play the sedulous ape", "have a bear by the tail", etc. And for being-based wild animal idiom, we find "as hungry as a bear", "like a bear with a sore head", "like a bat out of hell", "as blind as a bat". All these examples serve to illustrate the fact that event-domain cognitive model (ECM) and salience view is powerful in accounting for our English animal idioms.

\section{Mythical Animal Idioms}

This category of animals is an area where we can best see how historical or conventional cultural factors are brought into play in the interpretation of English animal idioms.

In English we have the idiom "dragon lady" to mean a woman with big power in her hands. Besides "dragon lady", we have "dragon's teeth" to mean source of discord. These two idioms have derived their symbolic meaning from English cultural context. In English culture, dragon is an evil mythical animal that can spit fire and do great damage on people's lives. Historically, dragon is a symbol for cruelty and wickedness by cultural conventions. This forms a sharp contrast to Chinese culture where the corresponding word "long (dragon)" is a time-honored symbol for royalty and supreme power. This sharp contrast is maybe due to different mental associations of the mythical animal "dragon" in Chinese culture. In Chinese legend, the dragon is highly versatile and adaptive to the environment since it can soar high up in the sky and dive deep down in water. And when it is in motion, it usually brings with it rain which is usually a welcome sight for farmers. Thus Chinese people always hold 
the mythical animal in high regard and nearly all the idioms in Chinese culture concerning "long" are positive.

\section{CONCLUSION}

Language is to a great extent shaped by culture and in turn reflects culture. It is the key to the decoding of culture in which it is embedded. Idioms are the living fossils of a language which affords us a good glimpse of culture in question. In this paper, we attempt to offer a new interpretation of the cognitive mechanism behind animal idioms. To be specific, instead of doing an overall study of English idioms as a whole, we have chosen a niche area, namely animal idioms in English as our research data. And for the theoretical framework, we have adopted the eventdomain cognitive model as our tool to shed light on our data. Language is like a tip of the iceberg called human cognition, and in thinking and organizing our experiences, an eventbased cognitive domain is the basic unit. In this domain guided by salience principle, different features of an action or a being under an event gets singled out and becomes salient in a specific animal idiom. And the whole total of this selection gives rise to a host of animal idioms which in turn enriches our thinking and expressions. Thus we hope that this research attempt can serve as a testing ground for further idiom related study. To study idioms can be such a meaningful attempt to research language and cognition and to make this attempt more fruitful we need to employ different linguistic theories and hopefully cognitive linguistic theories and perspectives can turn out to be a worthwhile attempt.

\section{REFERENCES}

[1] Brandt, P. A. (2005). Mental spaces and cognitive semantics: A critical comment. Journal of Pragmatics, 37, 1578-1594.

[2] Coulson, S. (2001). Semantic leaps: Frame shifting and conceptual blending in meaning construction (PP. 1-15). Cambridge: Cambridge University Press.

[3] Coulson, S. \& Oakley, T. (2000). Blending basics. Cognitive Linguistics, 11, 175-196.

[4] Coulson, S. \& Oakley, T. (2005). Blending and coded meaning: Literal and figurative meaning in cognitive semantics. Journal of Pragmatics, 37, 1510-1536.

[5] Croft, W. \& Cruse, D. A. (2004). Cognitive linguistics. Cambridge: Cambridge University Press.

[6] Dentith, S. (2000). Parody. London: Routledge.

[7] Fauconnier, G. (1985). Mental spaces. Cambridge: MIT Press.

[8] Fauconnier, G. (1994). Mental spaces: Aspects of meaning construction in natural language (pp. 86-100). New York: CUP.

[9] Fauconnier, G. (1997). Mappings in thought and language. New York: Cambridge University Press.

[10] Fauconnier, G. \& Turner, M. (1995). Conceptual integration and formal expression. In M. Johnson (Ed.), Journal of Metaphor and Symbolic Activity, 3, 183-204.

[11] Fauconnier, G. \& Turner, M. (1996). Blending as a central process of grammar. In A. Goldberg (Ed.). Conceptual structure, discourse and language (pp. 113-129). Stanford: Center of the Study of Language and Information (CSLI) Publications.

[12] Fauconnier, G. \& Turner, M. (2002). The way we think: Conceptual blending and the mind's hidden complexities. New York: Basic Books.
[13] Jaszczolt, K. M. (2004). Semantics and pragmatics: Meaning in language and discourse. Beijing: Peking University Press.

[14] Lakoff, G. (1987). Women, fire, and dangerous things: What categories reveal about the mind. Chicago: University of Chicago Press.

[15] Lakoff, G. \& Johnson, M. (1980). Metaphors we live by. Chicago: The University of Chicago Press.

[16] Lakoff, G. \& Johnson, M. (1999). Philosophy in the flesh: The embodied mind and its challenge to western thought. New York: Basic Books.

[17] Langacker, R. W. (1991/2002). Concept, image, and symbol: The cognitive basis of grammar. Berlin: Mounton de Gruyter.

[18] Leech, G. (1983). Principles of pragmatics. London: Longman.

[19] Levinson, S. C. (2001). Pragmatics. Beijing: Foreign Language Teaching and Research Press.

[20] Liu Chunbao. (2012). The English-Chinese Dictionary of Animal Metaphors. Beijing: The Commercial Press.

[21] Mey, J. (2001). Pragmatics: An Introduction. Beijing: Foreign Language Teaching and Research Press.

[22] Sperber, D. \& Wilson, D. (2001). Relevance: Communication and cognition. Beijing: Foreign Language Teaching and Research Press.

[23] Talmy, Leonard. (1985a). Force Dynamics in Language and Thought In William H. Eilfort, P. Kroeber, and K. Peterson (eds.). Papers from the Parasession on Causatives and Agentivity. Chicago: Chicago Linguistic Society.

[24] Talmy, Leonard. (1985b). Lexicalization Patterns: Semantic Structure in Lexical Forms. In Timothy Shopen(ed.). Language Typology and Syntactic Description, vol. 3. CUP.

[25] Talmy, Leonard. ( 1988). Force Dynamics in Language and Cognition. In Cognitive Science 12.

[26] Ungerer, F. \& Schmid, H. J. (2001). An introduction to cognitive linguistics. Beijing: Foreign Language Teaching and Research Press.

[27] Verschueren, J. (2000). Understanding pragmatics. Beijing: Foreign Language Teaching and Research Press. 